This item was submitted to Loughborough's Research Repository by the author.

Items in Figshare are protected by copyright, with all rights reserved, unless otherwise indicated.

\title{
Tribology of compression ring-to-cylinder contact at reversal
}

PLEASE CITE THE PUBLISHED VERSION

PUBLISHER

Professional Engineering Publishing / @ IMECHE

VERSION

VoR (Version of Record)

LICENCE

CC BY-NC-ND 4.0

REPOSITORY RECORD

Mishra, P.C., Sashi Balakrishnan, and Homer Rahnejat. 2019. "Tribology of Compression Ring-to-cylinder Contact at Reversal”. figshare. https://hdl.handle.net/2134/4697. 
This item was submitted to Loughborough's Institutional Repository (https://dspace.lboro.ac.uk/) by the author and is made available under the following Creative Commons Licence conditions.

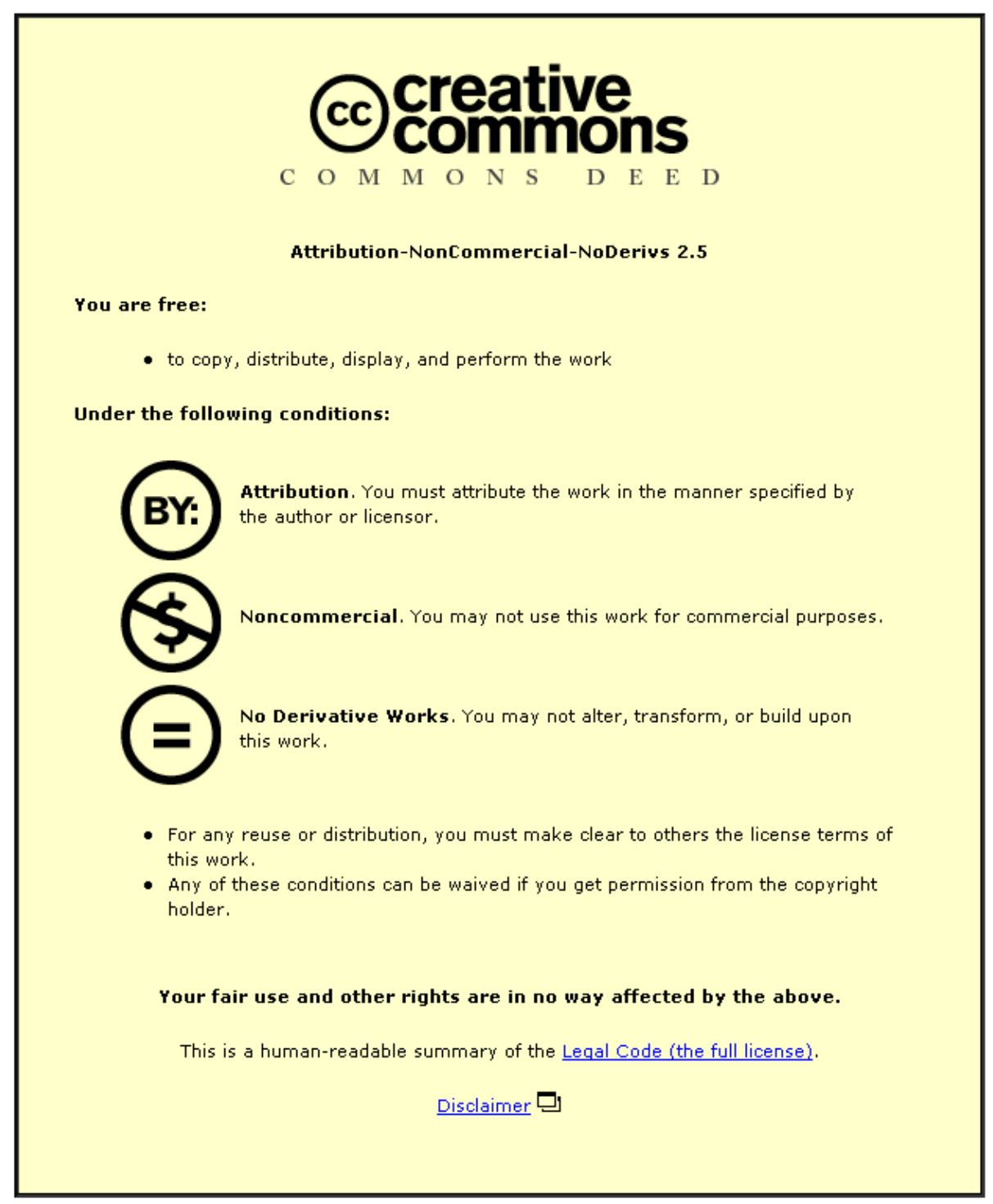

For the full text of this licence, please go to: http://creativecommons.org/licenses/by-nc-nd/2.5/ 


\title{
Tribology of compression ring-to-cylinder contact at reversal
}

P C Mishra, S Balakrishnan, and H Rahnejat ${ }^{*}$

Wolfson School of Mechanical and Manufacturing Engineering, University of Loughborough, Loughborough, Leicestershire, UK

The manuscript was received on 16 January 2008 and was accepted after revision for publication on 28 April 2008.

DOI: 10.1243/13506501JET410

\begin{abstract}
Piston ring-pack-to-cylinder contact accounts for one of the major sources of frictional losses in internal combustion engines. The regime of lubrication alters during the piston cycle because of the transient nature of applied load and kinematic contact conditions. Ring geometry, surface topography, and lubricant rheology also play an important role. The aim is to attain full fluid film lubrication, thus reducing friction because of boundary interactions. Therefore, accurate prediction of lubricant film thickness and pressure distribution constitutes the first step in a proper analysis of piston ring-cylinder conjunction. The creation of a gap through elastic deformation is sought in order to inhibit asperity tip interactions. The generated contact pressures in the lubricant film are due to combined entraining motion and squeeze film effect. The integrated pressure distribution balances the elastic force due to ring tension and the applied combustion pressure acting behind the ring. The article highlights a detailed analysis, which forms the basis for its future expansion to include the study of mixed regime of lubrication, which may be prevalent in some real engines.
\end{abstract}

Keywords: piston ring, ring deformation, lubrication

\section{INTRODUCTION}

The contact conjunction between the piston compression ring and the cylinder exhibits a range of lubrication regimes through the engine cycle, from mixed to hydrodynamic and onto elastohydrodynamic (EHD). Although during most part of the engine cycle the ring runs under hydrodynamic or mixed regime of lubrication, EHD conditions may also occur during the power stroke and at maximum combustion pressure. This usually occurs a few degrees past the top dead centre (TDC). From the tribological viewpoint, it is clear that the lubricant film thickness in this conjunction is one of the governing parameters of engine performance because of its significant share of frictional losses. Under transient conditions, film thickness shows a large variation and hence needs careful investigation. Frictional losses in this conjunction are affected

* Corresponding author: Wolfson School of Mechanical and Manufacturing Engineering, University of Loughborough, Loughborough, Leicestershire LE11 3TU, UK. email: h.rahnejat@lboro.ac.uk by inertial dynamics and modal behaviour (global deformation) of the ring, which are influenced by its material of construction, ring tension, and the applied gas pressure. Thus, the frictional behaviour of the compression ring is often a determining factor, limiting engine performance through its contact load carrying capacity.

For an incomplete circular ring of small crosssection, the basic classical equation of motion was first derived by Love [1]. He assumed an undeformed central radial axis in order to evaluate the global deformation of an incomplete circular ring in terms of ring tension, flexural rigidity, and an applied shear force. The incomplete circular ring was considered with different types of applied normal loads such as that for a slightly bent ring with an applied couple at its free ends in the radial plane. Other studies included the ring ends being subjected to opposing tension, as well as a couple applied at its ends perpendicular to the plane of the ring. Through these analyses, Love [1] obtained various modal frequencies for an incomplete circular ring, using the previous work of Mayer [2] and Timoshenko [3]. 
A study of flexural vibration of a curved beam in the form of an arc of a circle was carried out by Lamb [4] through theoretical interpretation. He proposed an in-plane vibration model about the neutral axis of the ring in the radial direction. A general equation and terminal conditions were established, and the simple statistical problem was solved for vibration of a free-free bar.

The global deformation of the ring follows its various mode shapes, generally referred to as its in-plane and out-of-plane modes, described by Tian [5]. Among these, there are several important ring characteristics, which affect lubrication between the ring and the cylinder. These include the degree of deformed ring conformance to the cylinder geometry, as well as ring twist and flutter. Tian [6] describes ring flutter and its effect on gas flow and oil transport, which can also have additional untoward effects in addition to the frictional losses. The analysis conducted by Tian [6] for a heavy duty diesel engine has shown the importance of ring-cylinder interactions for friction, wear, and oil consumption. A pure twist of an incomplete circular ring with a non-isotropic hollow cross-section using the method of toroidal elasticity was carried out by Lang [7]. Archer [8] also investigated small vibrations of a thin incomplete circular ring with a small cross-section, using the classical equations of motion. In this analysis, natural frequency and modes were found for rings with clamped ends. Vibrations were considered to occur in the radial plane of the ring, this being confined to its extensional mode.

The study of coupled twist-bending vibration of an incomplete elastic ring, using three-dimensional linear motion with generalized loading and viscous damping through the usual classical beam theory, was carried out by Ojalvo [9]. The equations of motion were solved for coupled out-of-plane bending and twisting dynamics. Results were generated for an incomplete circular ring, clamped at both ends. This study was a combination of the work of Love [1] and Archer [8], providing three-dimensional linear ring dynamics. Good agreement was shown with the approximate analysis reported by Den Hartog [10] and also by Brown [11]. Den Hartog [10] found the lowest natural frequency of a circular arc, which was clamped or hinged at its ends, using the Rayleigh-Ritz energy method. Both extensional and in-extensional vibrations were investigated in order to obtain the first- and second-natural frequencies. Brown's [11] investigation was concerned with the lateral vibration of a ring-shaped frame and its natural frequencies. Combined flexural and torsional vibrations perpendicular to the plane of the ring were investigated. The solution was an approximation, based on modifications made to the Rayleigh's energy method.
Okamoto and Sakai [12] estimated the contact pressure distribution of piston rings on the basis of ring shape, implementing the governing equation for curved beams. This involved initially measuring the piston ring-free contour and then calculating the contact pressure distribution on the ring circumference. Dunaevsky et al. [13] studied the three-dimensional distortion of a piston ring with an arbitrary crosssection in their study of oil flow and blow-by. It was noted that the three-dimensional distortion of the ring is either caused by installation stresses or operational parameters such as the gas pressure, induced friction, and thermal loads. Their model was applied to several typical cross-sections. A three-dimensional theory for piston ring installation and global distortion was then developed. The aim was to achieve good piston ring-to-cylinder liner conformance, taking into account the ring's physical and geometrical attributes. However, most analyses described thus far assume no bore distortion. In practice, significant thermo-elastic bore distortion may occur. This requires ring-bore conformability analysis to be carried out in addition to the methods highlighted above. Dunaevsky [14] and Chittenden and Priest [15] have carried out such analyses.

There have been many attempts to predict piston ring-to-cylinder bore or liner tribological performance, based on pressure-induced localized deformation, caused by EHD. Dowson et al. [16] carried out EHD lubrication analysis of the piston ring. Ruddy et al. [17] investigated the gas pressure within the ring pack for a large bore diesel engine, with the objective of overcoming the technical problems inherent in sealing a moving piston. It was noted that the ring gap could account for the gas leakage path, which is clearly as a result of combined local and global deformations of the ring. Knoll and Peeken [18] modelled the hydrodynamic lubrication of piston skirt and cylinder liner conjunction through an iterative method, using open end boundary condition to estimate the reaction force due to the generated pressures. Ma et al. [19] performed analysis of lubrication and friction for a complete piston ring pack with an improved oil availability model. A piston ring friction and lubrication model, capable of analysing asymmetric conditions, was developed to describe relative ring location, oil accumulation, and mixed and boundary lubrication in a ring-pack. Balakrishnan and Rahnejat [20] studied the transient conditions in the contact of piston skirt and ring-pack against cylinder liners during piston reversal. Their study showed changes in the regime of lubrication during reversal at or near the TDC. They also showed that fluid film lubrication can be encouraged by the introduction of lubricant retaining surface features. Their model only took into account local deformation of the contact 
caused by generated EHD pressures. The ring model was extended to include roughness and surfacemodified features on the ring by Teodorescu et al. [21], who showed an enhanced lubricant film thickness for rough contacts. Experimental validation of the predictions was undertaken by measuring film in a fired engine using an ultrasonic method, as reported by Dwyer-Joyce et al. [22]. This showed remarkable agreement with the results of Rahnejat et al. [23], but only for the piston-skirt-to-cylinder liner contact as the sensing head was larger than that required to resolve necessary measurements from the compression ring conjunction. Furthermore, the models presented in references [20] and [23] do not take into account the effect of global deformation of the ring under transient conditions.

It is therefore clear that a detailed lubrication model is necessary to include combined local and global deformations of the ring. This paper describes such an initial model, which combines EHD condition with in-plane deformation of the ring under isothermal condition. This is regarded as a necessary step towards the creation of a compression ring-specific model, which should then be extended to include roughness and thermal effects.

\section{THEORY}

\subsection{Elastic force due to ring global radial deformation}

Okamoto and Sakai [12] estimated the contact pressure distribution in the piston ring-bore conjunction by considering the ring as a beam element. They estimated the deformed ring shape using the bending moment concept, which is applied to a beam element fixed at one end (see Fig. 1). The correct pressure distribution between the piston ring and the cylinder was considered to be that which would result in stable sealing. A concept of least-square method was then

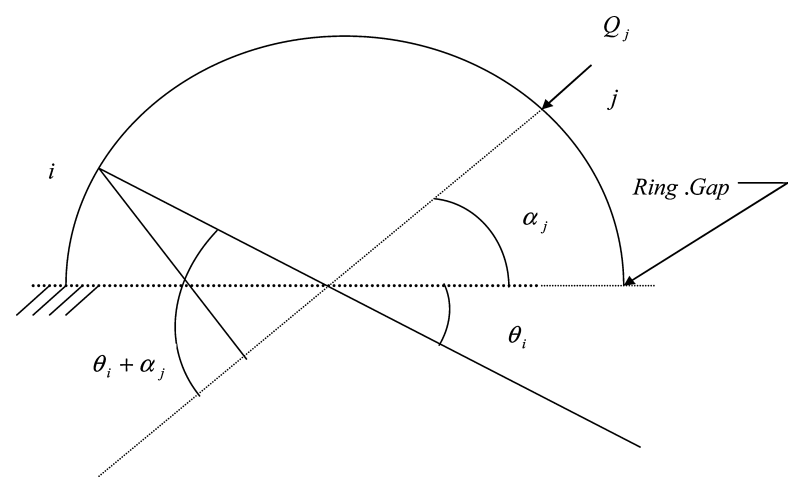

Fig. 1 Position of force and deformation in the general approach adopted to strike a compromise between the theoretically predicted ring contour and that obtained using a laser displacement meter. A few helpful formulations to this model were presented as follows.

The general expression for the radial displacement of a ring of nominal undeformed radius $r_{0}$ is given as $\Delta\left(\theta_{i}, \alpha_{j}\right)$, which means that $\Delta_{i, j}$ is the radial displacement at an arbitrary point $i$ due to the application of a load $Q_{j}$ at a point $j$. The bending moment at $i$ is thus obtained as

$$
M\left(\theta_{i}, \alpha_{j}\right)=Q_{j} r_{0} \sin \left(\theta_{i}+\alpha_{j}\right)
$$

By substituting for bending moment $M$, the radial displacement becomes

$$
\Delta\left(\theta_{i}, \alpha_{j}\right)=\frac{r_{0}^{3} Q_{j}}{E I} f\left(\theta_{i}, \alpha_{j}\right)
$$

where

$$
\begin{aligned}
f\left(\theta_{i}, \alpha_{j}\right)=a_{i, j}= & \cos \alpha_{j} \sin \theta_{i}\left(\frac{1}{2} \sin ^{2} \theta_{i}\right) \\
& +\cos \alpha_{j} \sin \theta_{i}\left(\frac{1}{4} \sin 2 \theta_{i}+\frac{\theta_{i}}{2}\right) \\
& -\cos \alpha_{j} \cos \theta_{i}\left(\frac{\theta_{i}}{2}-\frac{1}{4} \sin 2 \theta_{i}\right) \\
& -\sin \alpha_{j} \cos \theta_{i}\left(\frac{1}{2} \sin ^{2} \theta_{i}\right)
\end{aligned}
$$

The radial displacement (global in-plane deflection) $\Delta_{i, j}$ at any position $i$ due to the application of radial force $Q_{j}$ at position $j$ is thus given as

$$
\Delta(i, j)=\frac{r_{0}^{3}}{E I} \cdot a_{i j} \cdot Q_{j}
$$

The induced elastic pressure in the ring of face-width $b$ due to this deformation is

$$
P_{\mathrm{e}_{i j}}=\frac{E I}{2 \pi r_{0}^{4} b a_{i j}} \Delta_{i j}
$$

Hence, the elastic force acting outward on the ring is

$$
W_{\text {elastic }}=\sum \sum P_{\mathrm{e}_{i j}} \mathrm{~d} x \mathrm{~d} y
$$

\subsection{Gas force estimation}

The gas force acts upon the ring-bore contact in a radially outward direction. It depends on the net effect of gas pressure on the ring. Figure 2 shows the applied force detail on the ring surface.

In the figure, case I represents the reverse stroke (power stroke) of the engine cycle, which occurs after $360^{\circ}$. The trailing edge experiences the crank case pressure, whereas the leading edge is subject to 


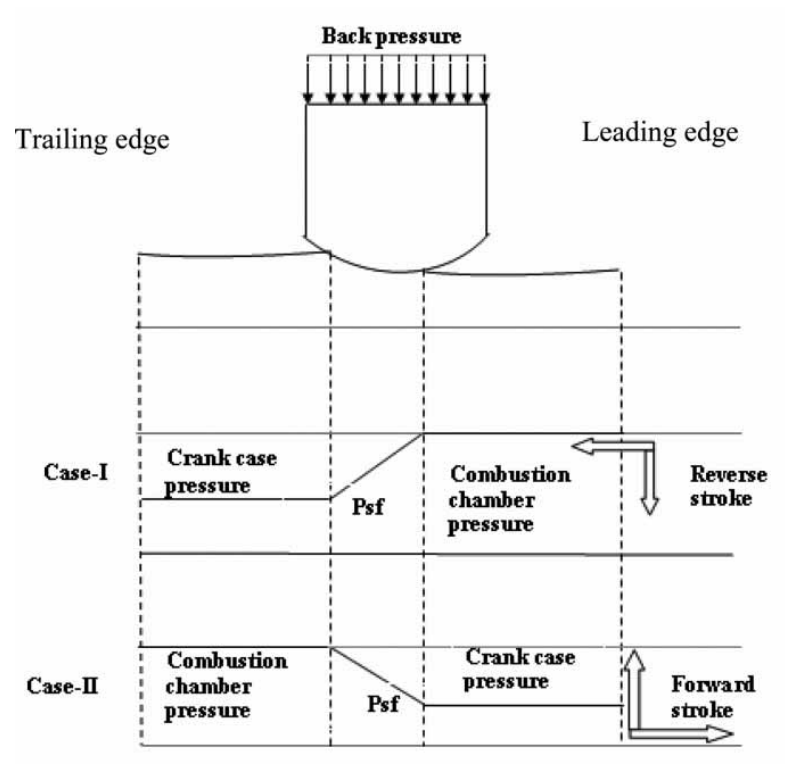

Fig. 2 Gas force action on the compression ring

the combustion pressure. The net static pressure on the ring face is, therefore, estimated to be

$$
\begin{aligned}
P s f= & P_{\text {crank_case }}+\left(P g_{\text {combustion }}-P_{\text {crank_case }}\right) \\
& \times \frac{x_{\text {inlet }}+x_{\text {cavitation }}}{2 b}
\end{aligned}
$$

Case II in the figure represents the forward stroke (compression stroke) of the engine cycle, when the leading edge experiences the combustion pressure and the trailing edge is subject to the crank case pressure. The net static pressure effect on the face of the ring is also the same as in equation (6).

The back of the ring is assumed always to experience the combustion pressure. Thus, the net gas force acting on the ring is

$$
P_{\text {gas }}=\left(P g_{\text {ing_back }}-P s f\right)
$$

These expressions assume an engine with a single ring. In practice, the ring-pack comprises two to four rings. For the simple single ring model described here, the crank pressure is assumed to act on its lower side.

Hence, the net normal force on the ring due to gas pressure is obtained as

$$
W_{\text {gas }}=\sum \sum P_{\text {gas }} \mathrm{d} x \mathrm{~d} y
$$

Therefore, $W_{\text {gas }}$ and $W_{\text {elastic }}$ act as the applied normal forces on the ring-bore contact. The addition of these constitutes the contact force, which by the virtue of Newton's third axiom should equate to the integrated EHD-generated pressures in the contact. Thus

$$
W_{\text {contact }}=W_{\text {gas }}+W_{\text {elastic }}
$$

\subsection{EHD conjunction}

A quasi-static analysis is carried out here. This represents the contact conditions at an instant of time, such as at the instance of maximum combustion force. A series of such quasi-static analyses can be performed around the region of interest, for example, in the vicinity of the TDC, where during the reversal in piston motion, momentary cessation of entraining motion occurs. The reversal deprives the contact of the main mechanism of fluid film lubrication, being due to the entrainment of lubricant into the contact, leaving any retention of fluid to be due to squeeze film action or by entrapment of the same in the rough contiguous surfaces. When a quasi-static analysis is undertaken, any contribution from squeeze film effect $\partial h / \partial t$ in Reynolds' equation is usually ignored, because this effect is largely due to transient changes to the film thickness, which can be approximated by

$$
\frac{\partial h_{i, j}}{\partial t} \approx \frac{1}{\Delta t}\left(h_{i, j(n)}-h_{i, j(n-1)}\right)
$$

$n$ represents a time step of size $\Delta t$.

Therefore, a series of successive quasi-static analyses would be required in order to adequately approximate the effect of squeeze velocity, normal to the plane of contact. Such analyses would approximate a full transient study with the drawback of very long computational times, largely of little value for most of the piston cycle, where tribological conditions are not critical such as at midcycle.

Noting that generated pressures in the piston ringbore's partially conforming contact are usually insufficient to significantly alter the lubricant rheology under isothermal conditions, one can ignore density changes, but account for piezo-viscous behaviour of the lubricant under sufficiently high pressures as: $\bar{\eta}=\eta / \eta_{0}=\exp ^{\left(\ln \eta_{0}+9.67\right)\left(-1+\left(1+5.1 \times 10^{-9} p\right)\right)}[\mathbf{2 4}]$ for isothermal conditions. Furthermore, the quantity of flow in the leakage side in the contact is negligible, compared with that in the direction of entraining motion. Thus, the form of Reynolds equation used in the current analysis becomes

$$
\frac{\partial}{\partial x}\left(\frac{h^{3}}{\eta} \frac{\partial p}{\partial x}\right)+\frac{\partial}{\partial y}\left(\frac{h^{3}}{\eta} \frac{\partial p}{\partial y}\right)=12\left[u_{\mathrm{av}} \frac{\partial h}{\partial x}+\frac{\partial h}{\partial t}\right]
$$

A series of quasi-static analyses carried out here are for the piston motion, corresponding to crank angles $357^{\circ}$ through to $363^{\circ}$, through the reversal at the TDC. The combustion curve for this study is shown in Fig. 3, which corresponds to a single-cylinder Honda $450 \mathrm{CRF}$ engine, used in racing dirt bikes. The global elastically deformed shape of its compression ring is used later to validate the global in-plane deformation model reported in section 2.1. 


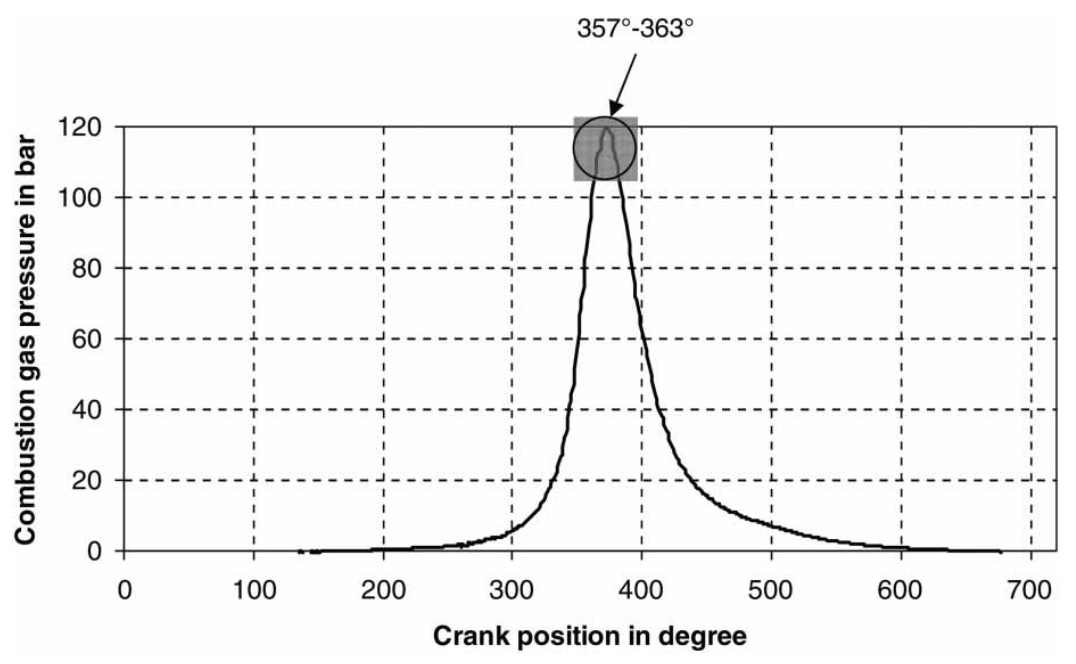

Fig. 3 The combustion curve for the investigated engine

In order to carry out the series of quasi-static EHD contact analyses, it is necessary to establish values for $\partial h / \partial t$ in the Reynolds equation. With the absence of a known film thickness at the beginning of the simulation, it is essential to commence at a location, where pure entraining motion may be assumed. Referring to the study of the same engine carried out by Rahnejat et al. [23], the entraining motion remains dominant up to the position defined by the crank angle of $357^{\circ}$.

The elastic film shape comprises an initial gap (rigid film $\left.h_{0}\right)$, the undeformed profile of the $\operatorname{ring}\left(S_{i, j}\right)$, enhanced by the global deformation of the ring, when placed in situ in the bore $\left(\Delta_{i, j}\right)$ and by the local deformation of the ring surface due to EHD pressures $\left(\delta_{i, j}\right)$. Thus

$$
h_{i, j}=h_{0}+S_{i, j}+\Delta_{i, j}+\delta_{i, j}
$$

The global deflection $\Delta_{i, j}$ is given by equations (3) and (4). The local deformation $\delta_{i, j}$ is obtained through a solution of generalized contact elasticity integral, yielding

$$
\delta_{i, j}=\frac{p_{i, j}}{\pi E^{\prime}} \mathbf{D}^{*}
$$

where the influence coefficient matrix $\mathbf{D}^{*}$ is given by Balakrishnan and Rahnejat [20] (Appendix 2) and

$$
\frac{1}{E^{\prime}}=\frac{1}{2}\left(\frac{1-v_{1}^{2}}{E_{1}}+\frac{1-v_{2}^{2}}{E_{2}}\right)
$$

\subsubsection{Solution procedure}

For a series of successive quasi-static analyses, it is essential for the converged elastic film shape from the previous analysis to be carried over to the next in order to obtain an estimate of squeeze film velocity, using equation (10). At each piston position, the combustion pressure is obtained from Fig. 3, and the gas force normal to the ring face-width is determined. This is added to the elastic force (ring tension), and the global deformation of the ring is established. This also determines the contact load and the initial gap, comprising the first three terms in equation (12) as the initial condition for each quasi-static step. Now the simultaneous solution of Reynolds equation with the film shape is undertaken in an iterative manner to find pressures $p_{i, j}$ and the corresponding films $h_{i, j}$. At each quasistatic step, all EHD pressures are initially assumed to be zero. All negative pressures are discarded in the iterative procedure. The exit (outlet) boundary conditions used are those of Reynolds, where $p=\mathrm{d} p / \mathrm{d} x=0$ at the rupture point $x=x_{\text {cavitation}}$. This condition does not fully concur with engine conditions, where an open-ended exit boundary may be present. However, it is the most widely used outlet condition $[16-19,21,23]$ and suffices for the cases where cavitation studies are not undertaken. The pressure convergence criterion within each step of successive quasi-static analysis (i.e. at each step of time) is

$$
\text { Error }^{\mathrm{p}}=\frac{\sum_{i}^{l} \sum_{i}^{m}\left|p_{i, j}^{K+1}-p_{i, j}^{K}\right|}{\sum_{i}^{l} \sum_{j}^{m}\left|p_{i, j}^{K+1}\right|} \leqslant 0.02
$$

where $K$ denotes the iteration number.

If pressure convergence is not met, then a new set of pressures is sought

$$
p_{i, j}^{K+1}=p_{i, j}^{K}+\Omega\left(p_{i, j}^{K+1}-p_{i, j}^{K}\right)
$$

The iteration process continues until the convergence criterion is satisfied. $\Omega$ is the under-relaxation factor, typically in the range of $0.3-0.7$. This method of solution is known as the low relaxation effective 
influence Newton method, described by Jalali-Vahid et al. [25].

The integrated pressure distribution must equate the contact load, determined by the combined elastic and gas force normal to the ring-bore contact surface, as indicated by equation (9). Thus

$$
W_{\text {contact }}=\int_{x} \int_{y} p_{i, j} \mathrm{~d} x \mathrm{~d} y
$$

Once convergence is obtained for the EHD pressures for each quasi-static step, load convergence is sought within a specified error

$$
\left|\frac{F_{\text {applied }}-W_{\text {contact }}}{F_{\text {applied }}}\right| \leqslant 0.01
$$

If load convergence remains unattained, then the rigid gap (initially the nominal clearance) $h_{0}$ between the ring and the bore is altered through relaxation, and the entire iterative procedure is repeated. Thus

$$
h_{0}^{k}=h_{0}^{k-1}-\left\{\xi_{\text {damping }}\left|\frac{F_{\text {applied }}-W_{\text {contact }}}{F_{\text {applied }}}\right|\right\}
$$

where $\xi_{\text {damping }}$ is a damping factor in the range $10^{-9}-10^{-8}$.

Table 1 Compression ring specification (after Okamoto and Sakai [12])

\begin{tabular}{ll}
\hline Ring details & Value \\
\hline Nominal diameter $(\mathrm{mm})$ & 82.2 \\
Axial width, $h_{1}(\mathrm{~mm})$ & 2 \\
Moment of inertia, $I\left(\mathrm{~mm}^{4}\right)$ & 4.06 \\
Modulus of elasticity, $E(\mathrm{GPa})$ & 203 \\
Radius of neutral line, $r_{0}(\mathrm{~mm})$ & 39.7 \\
Tangential force $(\mathrm{N})$ & 10 \\
Ovality (out-of-roundness) $(\mathrm{mm})$ & 0.29 \\
\hline
\end{tabular}

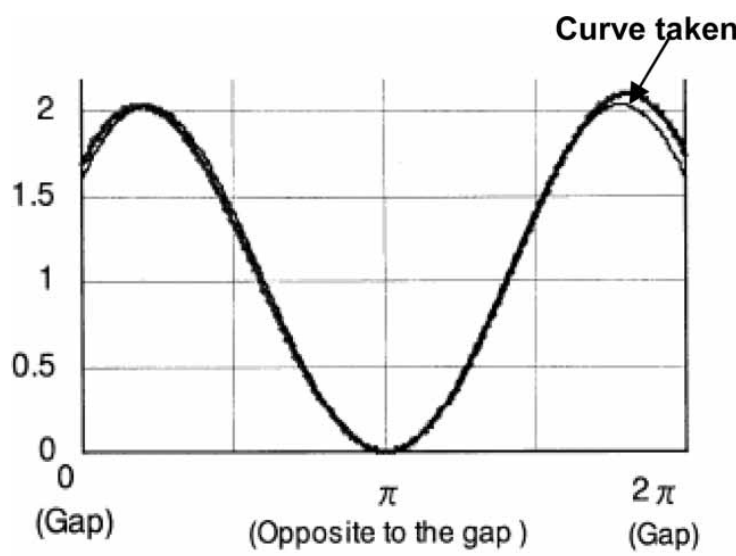

(a)

\section{RESULTS AND DISCUSSION}

\subsection{Radial in-plane ring deformation}

The piston ring is an incomplete circular ring, which is subjected to an initial outward ring tension during its installation. During piston motion, it is also subjected to variable outward gas pressures, which varies typically in the range of $0.5-99.6 \mathrm{bar}$. At the first stage of the analysis, validation for the method proposed in section 2.1 is sought for. This is very important, because the global deformation of an incomplete ring due its fitting into the bore determines the gap which affects the behaviour of the tribological contact. The validation is sought in two steps. First, comparison is made with the work of Okamoto and Sakai [12] under the same conditions (Table 1). These are shown in Figs 4(a) and (b). It can be seen that very good agreement is obtained.

The next step in the validation process is more important as it is made with the in situ measured deformed ring profile in the engine under investigation (Table 2). This is shown in Fig. 5. The measurement of the ring profile within the bore is carried out

Table 2 Data related to simulated engine condition

\begin{tabular}{ll}
\hline Physical-geometrical details & \multicolumn{1}{c}{ Value } \\
\hline Nominal diameter (mm) & 96 \\
Axial width (mm) & 1 \\
Ring radial depth (mm) & 3 \\
Modulus of elasticity (GPa) & 203 \\
Poisson's ratio & 0.23 \\
Moment of inertia of ring (m $\left.{ }^{4}\right)$ & $4.06 \times 10^{-12}$ \\
Engine operating speed (r/min) & 13000 \\
Lubricant dynamic viscosity at & 0.004 \\
$\quad$ atmospheric pressure $\left(\mathrm{Pa} \mathrm{s}^{-1}\right)$ & $10^{-8}$ \\
Piezo-viscosity index, $\alpha\left(\mathrm{Pa}^{-1}\right)$ & \\
\hline
\end{tabular}

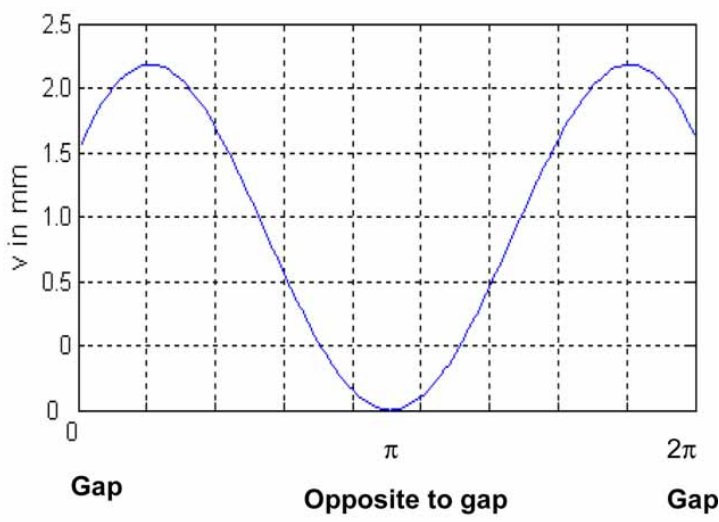

(b)

Fig. 4 Deformed compression ring profile: (a) after Okamoto and Sakai [12] and (b) current analysis 
on a coordinate-measuring machine with an accuracy of $1 \mu \mathrm{m}$. The free end gap of the ring was measured to be $10 \mathrm{~mm}$ prior to installation inside the bore. The outer and inner radii of the ring were also measured, using a needle type stylus, which avoids the skidding-related errors. Then, the ring was fitted into the bore and the end gap was measured again, this time being $0.1 \mathrm{~mm}$. Hence, the deformation resulted in the closure of the end gap by $9.9 \mathrm{~mm}$, which is almost the same as that predicted numerically. The outer and inner radii were also measured again in the fitted state of the ring. The radial deformation with respect to the inner radius is plotted in Fig. 5 for the purpose of validation.

Although the measured trend line differs somewhat from that predicted, the maximum values for deformation match within an error of $\sim 5$ per cent.

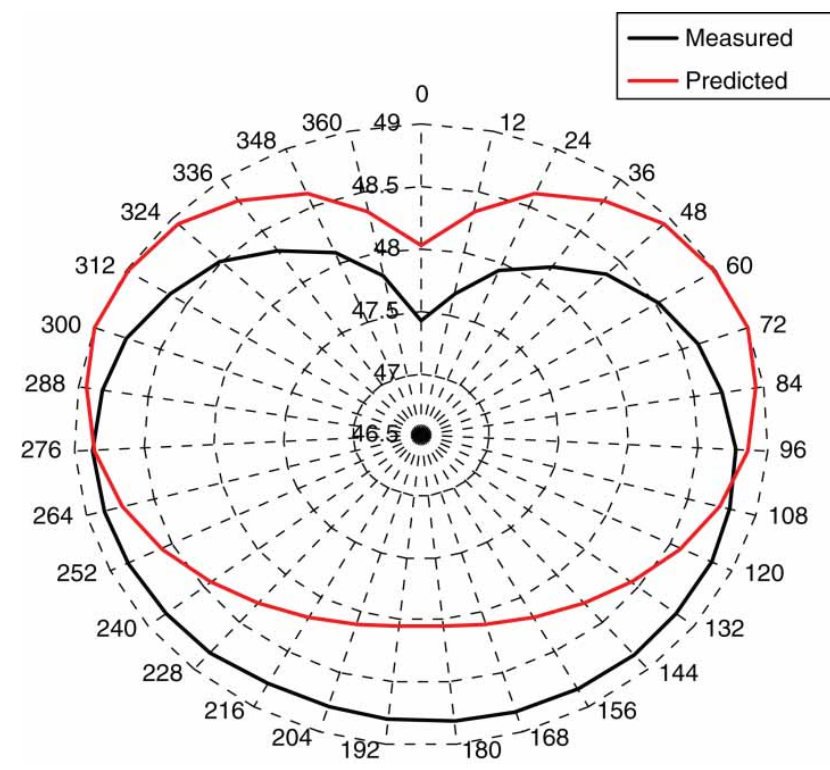

Fig. 5 Measured and predicted in situ fitted ring shape $(\mathrm{mm})$

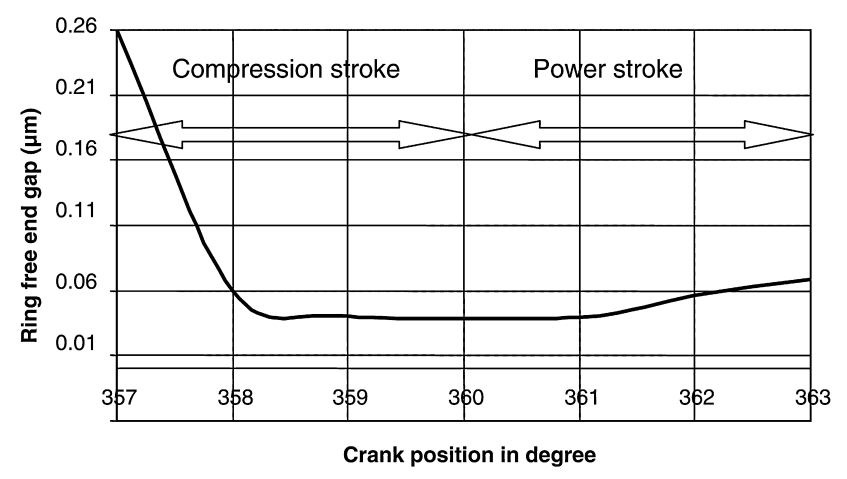

Fig. 6 Variation in the ring end gap during piston reversal at the TDC

\subsection{Quasi-static analyses}

Under dynamic conditions, the deformed shape of the ring alters because of changes in the chamber pressure (in compression stroke from $357^{\circ}$ to $360^{\circ}$ and in power stroke $360^{\circ}$ to $363^{\circ}$ in this analysis), whereas the ring tension force is assumed to remain unchanged. In a real engine, thermal effects caused by a combination of viscous and boundary friction also contribute to the changes in the ring shape due to thermal distortion. The in situ end gap reduces considerably from its value

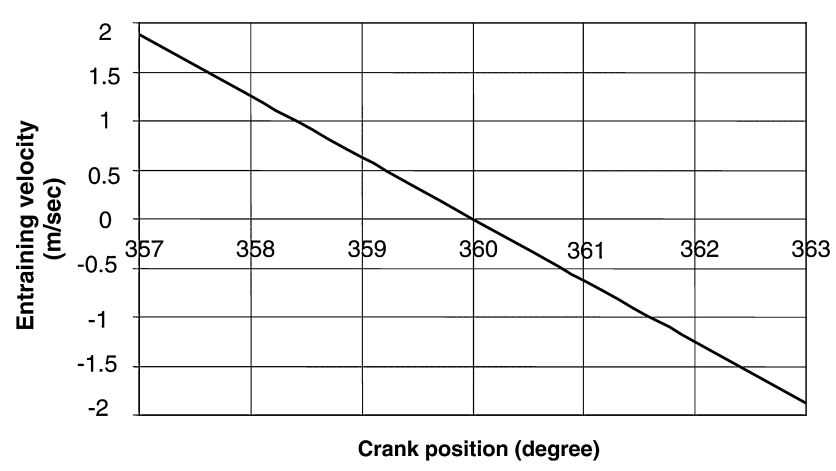

Fig. 7 Changes in the entraining velocity during reversal at the TDC

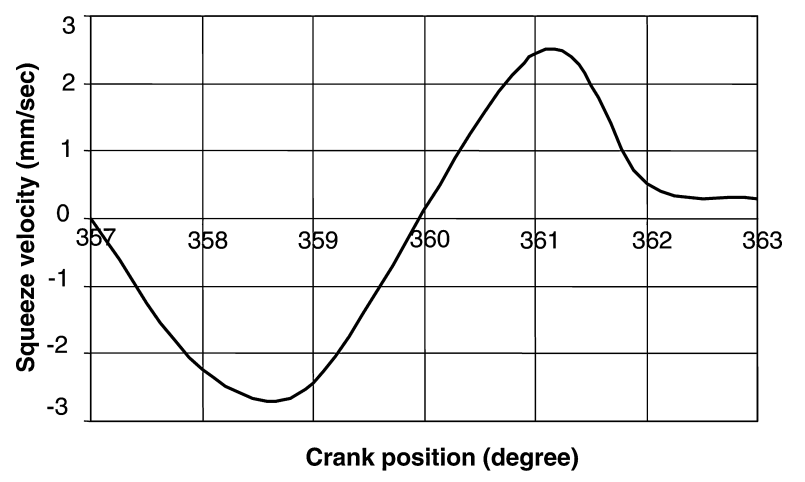

Fig. 8 Squeeze velocity variation during reversal at the TDC

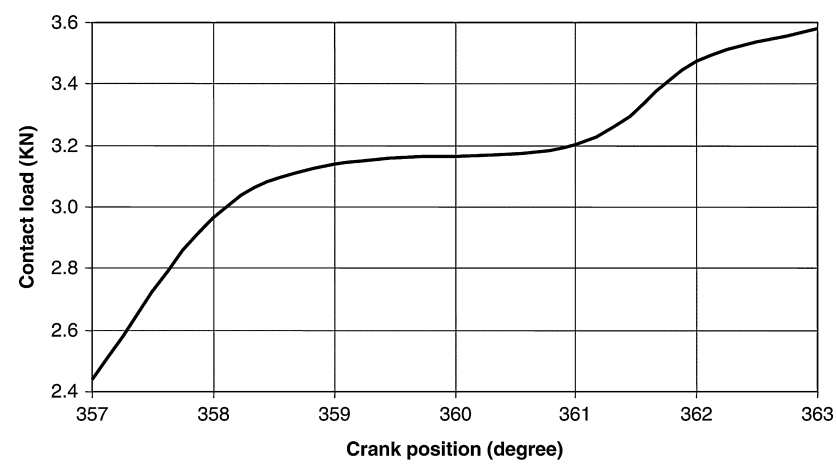

Fig. 9 Variation of the contact load during reversal at the TDC 

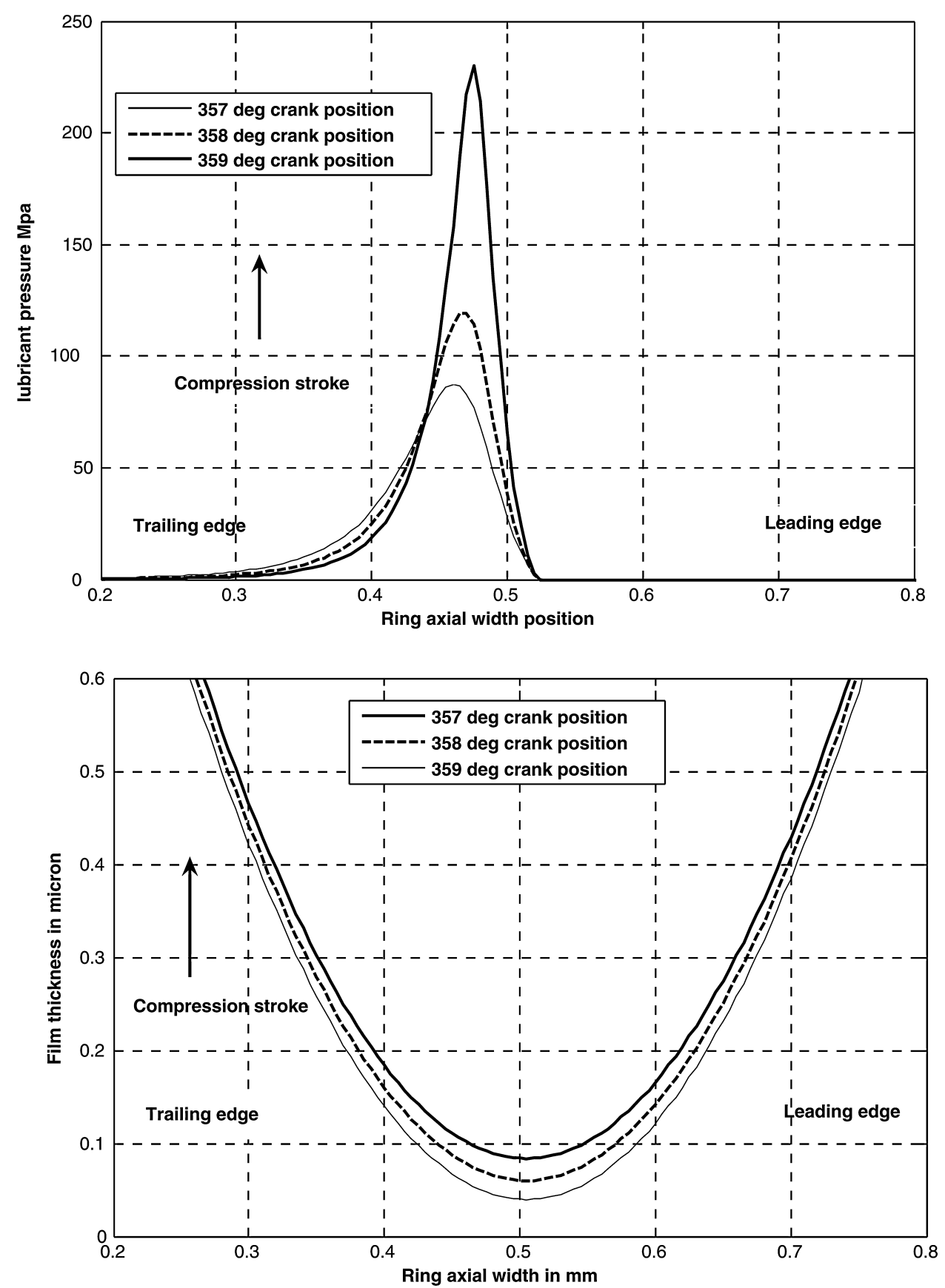

Fig. 10 Pressure distribution and film shape along the ring face-width in compression stroke in the vicinity of reversal at the TDC

of $0.1 \mathrm{~mm}$ due to the chamber and generated lubricant pressures of the order of micrometre or below. This affects its sealing action, which guards against blowby. The variation in the end gap is a good measure of ring shape change during transient condition. This is shown in Fig. 6.

The speed of entraining motion decreases linearly up to the TDC and reverses there (Fig. 7). The film thickness continues to diminish, thus the squeeze film velocity increases in a negative manner, corresponding to the approach of the contiguous bodies, and subsequently in a positive manner, denoting separation of the surfaces (Fig. 8). Only a very small squeeze film effect exists at TDC, and with the absence of any entraining motion there, a lubricant film of any appreciable thickness is unlikely. Thus, a mixed or boundary regime of lubrication would be expected, as noted by Rahnejat et al. [23] and Etsion [26] among others, who have included surface features on the cylinder liner surface to retain some level of fluid film lubrication.

The contact load variation during the series of quasistatic analyses reported here is shown in Fig. 9. It 

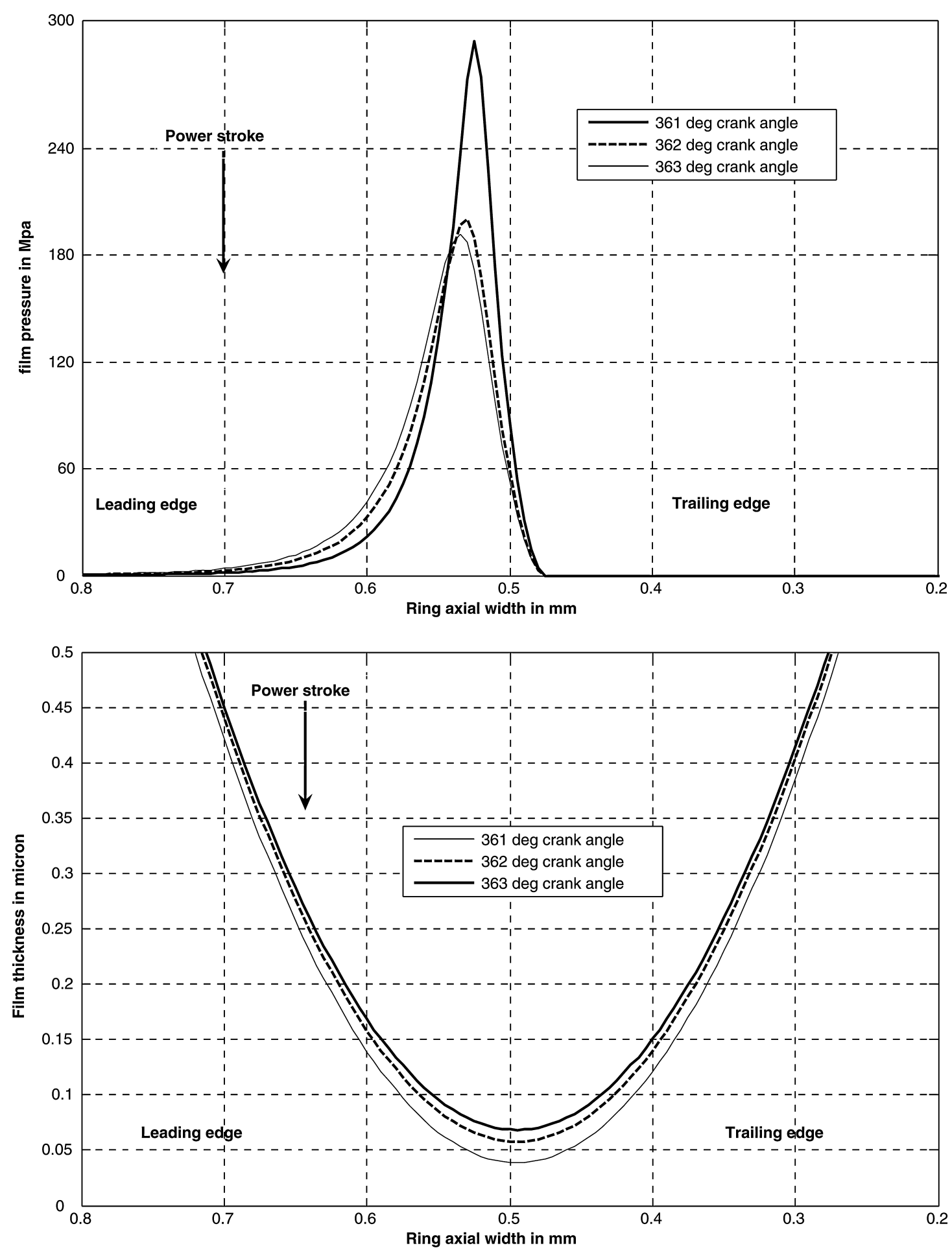

Fig. 11 Pressure distribution and film shape along the ring face-width in power stroke in the vicinity of reversal at the TDC

increases gradually due to compression up to the position of TDC, reaching a plateau. The subsequent increase in the power stroke continues up to a crank angle of $363^{\circ}$, at which the combustion force reaches its maximum value (Fig. 2).
The film thickness and corresponding pressure distributions in the axial direction of the ring facewidth are shown for the compression and power strokes prior to and after the reversal at the TDC in Figs 10 and 11, respectively. The pressure distributions 


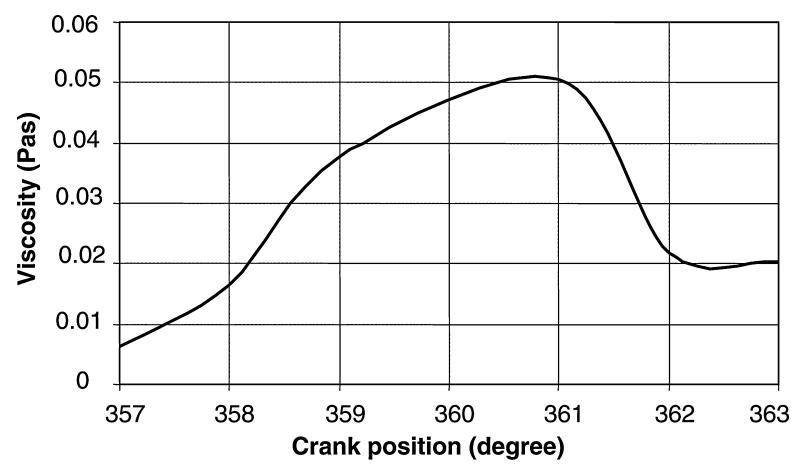

Fig. 12 Changes in the lubricant dynamic viscosity during reversal at the TDC

in all cases show a prevailing hydrodynamic regime of lubrication, as the generated pressures are insufficient to cause any significant localized deformation of the ring, but alter the viscosity of the lubricant by as much as an order of magnitude (Fig. 12). Referring back to the pressure distributions, note that the inlet trail in the compression stroke is at the top side of the ring, whereas in the power stroke, it is at its bottom face. As the film is at its least thickness at the TDC, the highest pressures occur there (Figs 10 and 11).

For the case studied here, the surface roughness of the liner and the ring are 0.1 and $0.125 \mu \mathrm{m} \mathrm{Ra}$, respectively. This gives a composite root mean square roughness value of $\sigma=0.16 \mu \mathrm{m}$. Figures 10 and 11 show instantaneous minimum film thickness values between 0.04 and $0.09 \mu \mathrm{m}$. A simple Stribeck analysis shows that the value of oil film parameter, $\lambda=$ $h_{\min } / \sigma$, would be consistently below unity, suggesting that during the reversal nearly a quarter of the ring
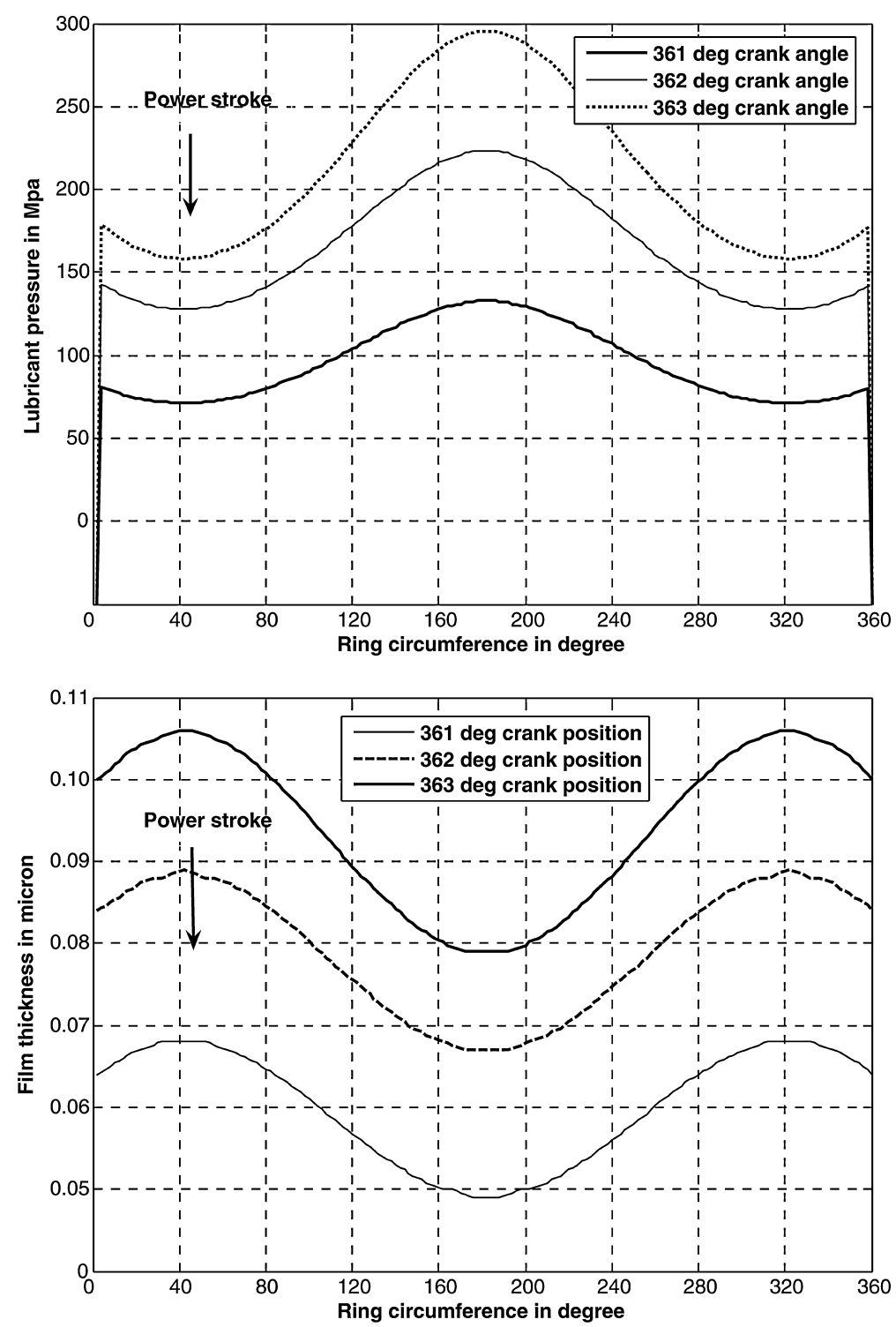

Fig. 13 Circumferential ring-liner pressure distribution and corresponding film shape following reversal at the TDC in power stroke 
face-width for the region of minimum film thickness in the circumferential direction suffers significant asperity interactions (Figs 11 and 13 for the circumferential film shape through its minimum thickness). However, it should be noted that asperities undergo ploughing (in elastic or plastic mode) in EHL contacts. Therefore, the $\lambda$ ratio can actually be different from that used in a simple Stribeck analysis highlighted here for convenience.

\section{CONCLUSION}

The analysis shows that the pressures generated in the compression ring-cylinder conjunction, even at contact loads of a few kilonewtons, are insufficient to cause significant local deformation of the contiguous solids, while increasing the lubricant viscosity by an order of magnitude. Thus, as far as localized conditions are concerned, a piezo-viscous rigid regime of lubrication results, which yields an insufficient film thickness in parts of the contact. A repercussion is increased friction due to asperity tip interactions at reversals (TDC results presented here). Therefore, it would be important to include asperity adhesion and ploughing deformation model to the analysis in order to obtain more representative predictions. Additionally, thermal effects, particularly due to friction, would not only affect the global distortion of the ring, but also further reduce lubricant viscosity, thus its pressure generation capability. These additions will form the future developments of the presented model.

\section{REFERENCES}

1 Love, A. E. H. A treatise on mathematical theory of elasticity, 1944 (Dover, New York).

2 Mayer, R. Uber Elastizitat und Stabilitat des geschlossenen und offenen Kreisbogens. Zeitschr.f.angewandte Math.u.Phys., 1921, Bd.61, 246-322.

3 Timoshenko, S. Elementary theories and problems, 1955 (D.Van Nostrand Co., London).

4 Lamb, H. On the flexure and vibrations of a curved bar. Proc. Lond. Math. Soc., 1888, 19, 365-376.

5 Tian, T. Dynamic behaviour of piston rings and their practical impact. Part I: ring flutter and ring collapse and their effects on gas flow and oil transport. Proc. Instn Mech. Engrs, Part J: J. Engineering Tribology, 2002, 216, 209-228.

6 Tian, T. Dynamic behaviour of piston rings and their practical impact. Part II: oil transport friction and wear of ring/liner interface and effects of piston and ring dynamics. Proc. Instn Mech. Engrs, Part J: J. Engineering Tribology, 2002, 216, 209-228.

7 Lang, A. Pure twist of a solid circular ring sector. Int. J. Solids Struct., 1983, 19(2), 131-140.

8 Archer, R. R. Small vibrations of thin incomplete circular rings. Int. J. Mech. Sci., 1959, 1, 45-56.
9 Ojalvo, I. U. Coupled twist-bending vibrations of incomplete elastic ring. Int. J. Mech. Sci., 1962, 4, 58-72.

10 Den Hartog, J. P. The lowest natural frequency of circular arc. Philos. Mag., 1928, 5(7), 400-408.

11 Brown, F. H. Lateral vibration of ring shaped frames. J. Franklin Inst., 1934, 217, 41-48.

12 Okamoto, M. and Sakai, I. Contact pressure distribution of piston rings - calculation based on piston ring contour. SAE technical paper 2001-01-0571, 2001, pp. 1-7.

13 Dunaevsky, V. V., Alexandrov, S., and Barlat, F. Analysis of three-dimensional distortions of the piston rings with arbitrary cross-section. SAE technical paper 200001-3453, 2000, pp. 1-7.

14 Dunaevsky, V. V. Analysis of distortions of cylinders and conformability of piston rings. STLE Tribol. Trans., 1990, 33(10), 33-40.

15 Chittenden, R. J. and Priest, M. Analysis of the piston assembly, bore distortion and future development. In Engine tribology (Ed. C. M. Taylor), 1993, pp. 241-270 (Elsevier, Amsterdam).

16 Dowson, D., Ruddy, B. L., and Economou, P. N. Elasto hydrodynamic lubrication of piston rings. Proc. R. Soc., 1983, A386, 409-430.

17 Ruddy, B., Dowson, D., and Economou, P. N. The prediction of gas pressure within ring packs of the larger bore diesel engine. J. Mech. Sci., 1981, 23(6), 295-304.

18 Knoll, G. D. and Peeken, H. J. Hydrodynamic lubrication of piston skirt. Trans. ASME J. Lubr. Technol., 1982, 104, 505-509.

19 Ma, M.-T., Smith, E. H., and Sherrington, I. Analysis of lubrication and friction for a complete piston ring pack with an improved oil availability model. Part 2: circumferentially variable film. Proc. Instn Mech. Engrs, Part J: J. Engineering Tribology, 1997, 211, 17-27.

20 Balakrishnan, S. and Rahnejat, H. Isothermal transient analysis of piston skirt-to-cylinder wall contacts under combined axial-lateral-tilting motion. J. Phys. D Appl. Phys., 2005, 38, 787-799.

21 Teodorescu, M., Balakrishnan, S., Rahnejat, H., HowellSmith, S., and Dowson, D. Tribological analysis within a multi-physics framework. In Proceedings of the 31st Leeds-Lyon Symposium, Elsevier, Leeds, UK, September 2004.

22 Dwyer-Joyce, R. S., Green, D. A., Balakrishnan, S., Harper, P., Lewis, R., Howell-Smith, S., King, P. D., and Rahnejat, $\mathbf{H}$. The measurement of liner-piston skirt oil film thickness by an ultrasonic means. SAE paper 2006-01-0648, 2006.

23 Rahnejat, H., Balakrishnan, S., King, P. D., and HowellSmith, S. In-cylinder friction reduction using a surface finish optimization technique. Proc. IMechE, Part D: J. Automobile Engineering, 2006, 220(D9), 1309-1318.

24 Roelands, C. J. A. Correlation aspects of the viscositytemperature-pressure relationships of lubricating oils, 1966 (Groningen, Druk VRB Kleine der A3-4).

25 Jalali-Vahid, D., Rahnejat, H., Gohar, R., and Jin, Z. M. Prediction of oil-film thickness and shape in elliptical point contacts under combined rolling and sliding motion. Proc. Instn Mech. Engrs, Part J: J. Engineering Tribology, 2000, 214, 427-437.

26 Etsion, I. State of the art in laser surface. Trans. ASME J. Tribol., 2005, 127(1), 248-253. 


\section{APPENDIX 1}

\section{Notation}

$a_{i, j}$
$\bar{a}$
$\frac{b}{b}$

error $^{\mathrm{p}}$

$E_{1}$

$E_{2}$

$E^{\prime}$

$f\left(\theta_{i}, \alpha_{j}\right)$

$F_{\text {applied }}$

$h_{0}, h$

$i, j$

I

$K$

$M\left(\theta_{i}, \alpha_{j}\right)$

$p_{i, j}$

$P_{\text {crank_case }}$

$P_{\mathrm{e}_{i j}}$

$P_{\text {gas }}$

$P g_{\text {combustion }}$

$P g_{\text {ring_back }}$

Psf

$Q_{j}$

$r$

$r_{0}$

$S_{i, j}$

$t$ function related to radial ring

deformation ( $\mathrm{mm}$ )

large side of the rectangular contact

( $\mu \mathrm{m})$

ring axial width (mm)

small side of the rectangular contact

$(\mu \mathrm{m})$

error for pressure computation

modulus of elasticity for the ring

surface $\left(\mathrm{N} / \mathrm{m}^{2}\right)$

modulus of elasticity for the

liner/bore surface $\left(\mathrm{N} / \mathrm{m}^{2}\right)$

apparent modulus of elasticity $\left(\mathrm{N} / \mathrm{m}^{2}\right)$

function related to radial ring

deformation

applied load $(\mathrm{N})$

undeformed minimum gap size and

film thickness $(\mu \mathrm{m})$

position vectors in ring deformation

measurement

area moment of inertia of incomplete

ring $\left(\mathrm{mm}^{4}\right)$

iteration step

moment due to displacement $(\mathrm{N} \mathrm{m})$

hydrodynamic pressure generated in

the film $\left(\mathrm{N} / \mathrm{m}^{2}\right)$

pressure in the crank case end of the ring $\left(\mathrm{N} / \mathrm{m}^{2}\right)$

radial elastic pressure in the ring

$\left(\mathrm{N} / \mathrm{m}^{2}\right)$

net gas pressure in the ring $\left(\mathrm{N} / \mathrm{m}^{2}\right)$

pressure in the combustion chamber end of the ring $\left(\mathrm{N} / \mathrm{m}^{2}\right)$

pressure in the back of the ring

$\left(\mathrm{N} / \mathrm{m}^{2}\right)$

effective static pressure in the front of the ring $\left(\mathrm{N} / \mathrm{m}^{2}\right)$

force applied at various locations in the ring circumference $(\mathrm{N})$

radius of ring after deformation ( $\mathrm{mm}$ )

initial radius of curvature of ring

(mm)

shape function related to ring profile

(mm)

time (s)

\begin{tabular}{|c|c|}
\hline$u_{\mathrm{av}}, v_{\mathrm{av}}$ & velocity of ring reciprocation $(\mathrm{m} / \mathrm{s})$ \\
\hline$\nu\left(\theta_{i}, \alpha_{j}\right)$ & $\begin{array}{l}\text { tangential component of ring } \\
\text { deformation (mm) }\end{array}$ \\
\hline$W_{\text {contact }}$ & $\begin{array}{l}\text { calculated reaction force in the } \\
\text { film }(\mathrm{N})\end{array}$ \\
\hline$W_{\text {elastic }}$ & force due to elastic pressure $(\mathrm{N})$ \\
\hline$W_{\text {gas }}$ & $\begin{array}{l}\text { force due to the effective gas pressure } \\
(\mathrm{N})\end{array}$ \\
\hline$x, y$ & $\begin{array}{l}\text { directional coordinates in the axial } \\
\text { and circumferential directions }\end{array}$ \\
\hline$x_{\text {cavitation }}$ & position of the starting of cavitation \\
\hline$x_{\text {inlet }}$ & $\begin{array}{l}\text { inlet position in the ring axial } \\
\text { direction }\end{array}$ \\
\hline$\alpha$ & piezo-viscosity index \\
\hline$\alpha_{j}$ & $\begin{array}{l}\text { position of application of force } \\
\text { (radian) }\end{array}$ \\
\hline$\delta_{i, j}$ & elastic deformation of the ring $(\mathrm{mm})$ \\
\hline$\Delta_{i, j}$ & deformed ring shape (mm) \\
\hline$\eta$ & lubricant dynamic viscosity (Pa s) \\
\hline$\eta_{0}$ & $\begin{array}{l}\text { dynamic viscosity at atmospheric } \\
\text { pressure ( } \mathrm{Pa} \mathrm{s} \text { ) }\end{array}$ \\
\hline $\bar{\eta}$ & non-dimensional viscosity \\
\hline$\theta_{i}$ & position of deformation (radian) \\
\hline$v_{1}$ & Poisson's ratio for ring surface \\
\hline$v_{2}$ & Poisson's ratio for liner/bore surface \\
\hline$\xi_{\text {dam }}$ & damping factor \\
\hline & tor \\
\hline
\end{tabular}

\section{APPENDIX 2}

$$
\begin{aligned}
\mathbf{D}^{*}= & (x+\bar{b}) \ln \frac{(y+\bar{a})+\left[(y+\bar{a})^{2}+(x+\bar{b})^{2}\right]^{1 / 2}}{(y-\bar{a})+\left[(y-\bar{a})^{2}+(x+\bar{b})^{2}\right]^{1 / 2}} \\
& +(y+\bar{a}) \ln \frac{(x+\bar{b})+\left[(y+\bar{a})^{2}+(x+\bar{b})^{2}\right]^{1 / 2}}{(x-\bar{b})+\left[(y+\bar{a})^{2}+(x-\bar{b})^{2}\right]^{1 / 2}} \\
& +(x-\bar{b}) \ln \frac{(y-\bar{a})+\left[(y-\bar{a})^{2}+(x-\bar{b})^{2}\right]^{1 / 2}}{(y+\bar{a})+\left[(y+\bar{a})^{2}+(x-\bar{b})^{2}\right]^{1 / 2}} \\
& +(y-\bar{a}) \ln \frac{(x-\bar{b})+\left[(y-\bar{a})^{2}+(x-\bar{b})^{2}\right]^{1 / 2}}{(x+\bar{b})+\left[(y-\bar{a})^{2}+(x+\bar{b})^{2}\right]^{1 / 2}}
\end{aligned}
$$

